\title{
Liver transplantation. A twenty-year anniversary worthy celebration
}

\author{
Transplante de fígado. Aniversário de vinte anos, que vale a pena comemorar
}

Orlando de Castro e Silva Jr ${ }^{1}$ (D), Ana de Lourdes Candolo Martinelli ${ }^{2}$ (D.

\section{Our history}

Twenty years ago, on May 1st, 2001, the first liver transplant was performed at the University Hospital, Faculty of Medicine of Ribeirão Preto, University of São Paulo (HC-FMRP-USP), Brazil.1,2 A team of forty professionals was assembled for this inaugural enterprise, consisting of surgeons, clinicians, anesthesiologists, nurses, nurse technicians and laboratory auxiliaries. In addition, we counted on the support of the Sectors of Radiology, Blood Center, Physiotherapy and Nutrition of the HC-FMRP-USP. Moreover, an unconditional support from the Department of Pathology in the person of Professor Sérgio Zucoloto was essential for the success of the program. Considering the importance of the analysis of the hepatic structure not only for the surgical procedure per se but also to evaluate complications following the procedure and the evolutions of liver injury, the pathologist is a fundamental figure, as all the members of his team.

The work of all these professionals culminated with the creation of the Integrated Group of Liver Transplantation of our institution, the HCFMRP-USP. The complete hospital infrastructure was ready in the beginning of $2000 .^{3}$ The first year of the new century brought with it a clinical-surgical procedure that had been prepared meticulously during the last decade of the 20th century, the performance of the first liver transplantation in humans in our institution, the expected milestone in a long history. Then, we provided a logo for the Group that represented the spirit of the transplant program. We asked the graduate student of surgery A A L A Lima to idealize this logo and that can be seen in figure 1

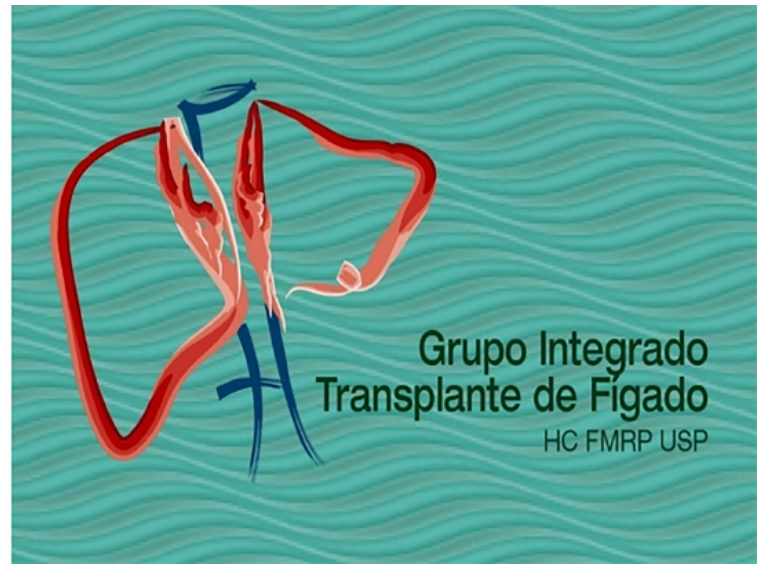

Figure 1. Logo of the Integrated Group of Liver Transplantation created by Graduate student of surgery, Adriana A L A Lima, at my request. ${ }^{\text {Ocs.r }}$

1. Full Professor Department of Surgery and Anatomy. University of São Paulo. Ribeirão Preto School of Medicine, Ribeirão Preto, (SP), Brazil

2. Associated Professor Department of Medicine. University of São Paulo. Ribeirão Preto School of Medicine, Ribeirão Preto, (SP), Brazil 
Based on the nature of FMRP centered on research and coinciding with all effort to establish the liver transplantation program, it was created an ample research environment directed to the experimental study of liver diseases and especially to the experimental technical training for liver transplantation in dogs, rats and pigs. At that time, it was permitted and ethical to conduct surgical training and research with dogs. ${ }^{3,4}$

The establishment of the liver transplantation procedure brought the potential of conferring to our Institution the status of Reference Service for the treatment of liver diseases. In addition to transplantation itself, there would be progress in the diagnosis and treatment of several liver diseases including liver cancer in its various stages. Considering the multidisciplinary nature of liver transplantation, improvements in the technicalsurgical, clinical and anesthetic training of the team members would occur. ${ }^{4}$ It should be stressed that the establishment of the liver transplantation program comprise a highly complex procedure, a characteristic that generates, absorbs and transfers science and technology in the institution where it is performed. This is, per se, a procedure to be performed on an institution which must involve a team of specialists with high ethical, technical, professional, scientific, academic and care standard. 4,5,6

There were great expectations at the beginning of the liver transplant program of HC-FMRP-USP as a true institutional challenge. Guaranteeing people's life by exchanging an insufficient liver by a healthy one, extracted from another person, represents one of the greatest advances of medicine. A new chapter start to be written in their history when the original physical structure is modified, and they accept as their own a foreign organ.

\section{Important facts in the general Liver Transplantation history}

In the West, organ and homologous and heterologous tissue transplants began more than two hundred years ago with the experiments conducted on humans and animals by Duhamell du Monceau, John Hunter and Jacques Louis Reverdin. However, it was in the twentieth century that three factors had a definitive influence on the possibility of solid organ transplantation: the establishment of the principle of vascular anastomoses by Alexis Carrel, in 1901; the notion that hypothermia could maintain the functional viability of an organ ex vivo, and the development of the immunological bases of the rejection phenomena in the 1940 s by Peter Brian Medawar, a Brazilian biologist born in Petrópolis, who left Brazil at the age of 15 and conducted his studies in England.

Thomas Starzl, after several experimental studies on hepatotrophic factors in parallel to experimental liver transplantation in the 1950's and '60's, performed the first successful experimental liver transplant in a human being in 1967. It occurred after some frustrated initial attempts due to the complicated postoperative period, typical of the complex surgical procedure. Later on, in the 80 's and 90 's, liver transplantation became a routine therapeutical procedure for patients with endstage chronic liver diseases. The advent of cyclosporin in 1980, associated to the use of new solutions for organ preservation at the end of the 80 's, the creation of new surgical techniques in the early 90's and the refinement of anesthetic techniques made possible to put the liver transplantation in its prominent place in the medical-surgical therapy all over the world. $6,7,8,9,10$

\section{The beginning of the Service of Hepatology in our Institution}

The main indications for liver transplantation are end stage of chronic liver diseases caused by chronic viral hepatitis $C$ and hepatitis $B$, abusive alcohol intake and, more recently, metabolic associated fat liver disease. A severe acute hepatic injury associated to viral hepatitis ( $A, B$ and $C$ ), drug induced liver injury, use of phytotherapeutic substances, teas, herbs, and supplements are also indication for liver transplantation. $5,8,10$ Within this context, the development of a solid Service of Hepatology at HCFMRP-USP was fundamental since its early stage. It started in the mid-80s with experimental studies conducted by us in our Master's and Doctoral thesis under the guidance of Professors Ruy Ferreira Santos, Reginaldo Ceneviva, Ulysses Meneghelli and Sergio Zucoloto, who supported us in the mission of developing Clinical-Surgical Hepatology at our institution. It was our responsibility to set up laboratories, to train younger habilitated personnel and to prepare them for continued scientific and professional training in clinical and surgical Hepatology. Concomitantly, visits to state-of-the-art 
services abroad were of fundamental importance, especially regarding the clinical part of transplantation. ${ }^{3}$

A close contact with professors at the Faculty of Medicine of Sao Paulo-USP (FMSP-USP) since 1980 decade, Professors Silvano Raia, Sérgio Mies and Flair Carrilho was very important for our scientific formation. I ocsjr worked as Assistant Professor at FMSP-USP with Professors Silvano Raia and Sérgio Mies, when it was possible to work with clinical and experimental liver transplantation with extremely valuable results for my development.

Also, it was very important for our clinical development in the area of liver transplantation a close contact with researchers at the Clinical and Provincial Hospital of Barcelona, particularly with Professor Antoni Rimola who gave to both of us the opportunity to spend some months visiting the service of Liver transplant in the Hospital Clinic of Barcelona.

The link among researchers from FMRP-USP, FMSP-USP and Hospital Clinic of Barcelona make possible the establishment of the Scientific Biannual Meeting of Hepatology between USP and Barcelona since 2002. This also contributed for the development of the Hepatology in our institution. In this project was fundamental the participation of Professors from Hospital Clinic of Barcelona, Juan Rodés, Vicente Arroyo, Pere Ginès and Luis Grande and, from FMSPUSP, Professor Flair Carrilho.

The importance of the Hepatology and the Liver Transplantation Program for Ribeirão Preto and region. Situation of organ donation in Brazil in 2001.

The city of Ribeirão Preto and nearby towns, forming the Ribeirão Preto region, which counted on HC-FMRP-USP as a reference institution for medical care, could not be left out of the process needed for the treatment and possible cure of end-stage liver disease, a process carried out worldwide with good results. It should be pointed out here that, already in 2000, the number of patients with chronic liver diseases was growing significantly all over the world, including Brazil and our region. This was mainly due to the large number of patients with viral hepatitis who were unaware of the diagnosis of the infection since most cases have an asymptomatic course during the initial phases, which becomes symptomatic during the advanced phases of the disease. Within this context, the implementation of the Liver Transplant Service of HC-FMRP-USP in 2000 permitted offering curative treatment to patients with acute or chronic severe liver disease. Therefore, it became necessary to set up and increase the number of outpatient clinics. ${ }^{3}$

In 2005, the Liver Transplant Unit was inaugurated, with the capacity for seven patients under isolation, then becoming the Center of Organ Transplantation in 2019, with the capacity to treat a larger number of patients who needed a liver transplant as a therapeutic option. ${ }^{3,11}$

Currently, outpatient clinics Run every day of the week to care for patients with liver diseases. The number of these visits has increased significantly, partially reflecting the possibility of offering a liver transplant in the therapeutic arsenal. In 2016 a total of 13,222 patients were treated at these clinics for chronic liver diseases secondary to viral hepatitis, alcohol abuse, metabolic and autoimmune diseases, hepatocellular carcinomas, and liver pre-transplant. As a comparison between years, 2,100 cases of viral hepatitis were treated in 2006 and 7,200 cases in 2016, 75 cases of cancer of the liver in 2006 and 960 cases in 2016. And the number of cases continues to increase

So far, 521 liver transplants have been performed by the Liver Transplant Program of HC-FMRP, 50 of them were done last year. Since 2019, the program is under the coordination of Professor Ajith Kumar Sakarankutty, With the capacity to perform up to 40 liver transplants per year the Service has established the HC-FMRP-USP as a reference for the care of any and all clinical or surgical liver diseases.

The possibility of performing a liver transplant in a hospital demonstrates, in addition to the availability of a complex institutional structure, the unshakable will of people and the organizational quality of our Unified Health System (SUS). Democratically, any Brazilian citizen has free access to a liver transplant, this being a duty of the State and a right of the citizens according to the 1988 National Constitution. In this scenario, in the second semester of 1999 we started the Liver Transplant Program of HC-FMRP-USP after accreditation of both the hospital and the specialized medical team according to Ordinance $n^{\circ} 812$ of December 29, 1999. As it is 
still the case today, in that year organ donation was the Achilles' heel of the transplant process.

In 2001, Brazil had 3 to 4 donors per million population (pmp), while, in comparison, Spain had about $34 \mathrm{pmp}$. Refusal by the family represented up to $47 \%$ of failed donations, a situation that is practically unchanged nowadays. The first patient was then enrolled in the waiting list and we were then able to perform the first liver transplant on May 1st, 2001, Sair Figure 2, panel A and B. There were three patients on the waiting list, and the first of them was the one who was effectively transplanted.

Details for the first liver transplantation in our

\section{Institution}

The donor surgery started at 20:00 h of May 1st in the Emergency Unit of the University Hospital and the surgical procedure of the recipient was scheduled for 2:00 a.m., May 2. I, ocssr had just returned from a congress in Vitória ES at 7:00 pm and was trying to rest and concentrate in the habitual preparation for that so long-awaited surgery. my cell phone rang, and, on the other end of the line, a hospital employee gave me the news: "Professor, the air conditioner of the operating room stopped functioning. We will have to cancel the transplant ". Iocssr immediately replied: "We will not cancel. This transplant must take place" "there is a patient clinically and emotionally ready and a team ready and anxious to perform it". It would be the first liver transplant and it did occur as planned. The air conditioning was repaired before midnight, the anesthesiologists started the procedure and the surgery began at 2 hours and 45 minutes am. (figure 2, panel A and B). Members of the Integrated Liver Transplantation Group together with the transplanted patient, in 2001, as can be seen in figure 3 panels,

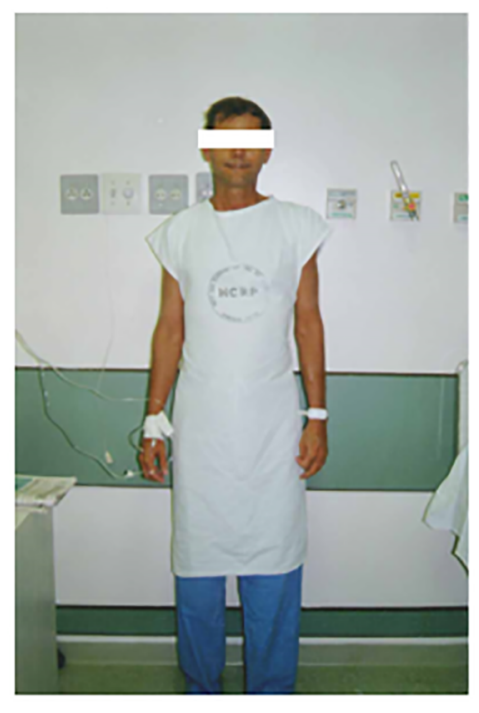

\section{Panel A}

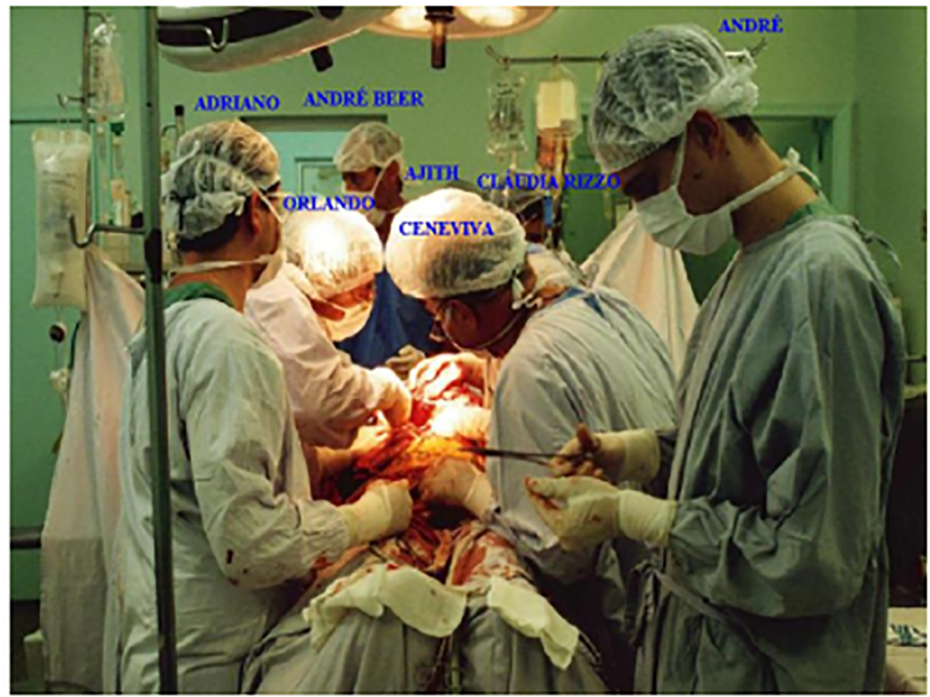

Panel B

Figure 2 Panel A. Photograph of the First transplanted patient. E.A.P., male, 48 years, from Campinas -SP. Panel B. Photograph of the first liver transplantation at HC-FMRP-USP. Surgical Team: Prof.Dr. Orlando de Castro e Silva Júnior, Prof.Dr. Reginaldo Ceneviva; Dr. Ajith K. Sankarankutty, Dr. Gustavo R. de Oliveira, Dr. Enio David Mente and Dr. Adriano Brunetti. Anesthetic team:Dr. Cláudia Carvalho, Dr.Luiz Vicente Garcia and Dr. André Beer Jr. 


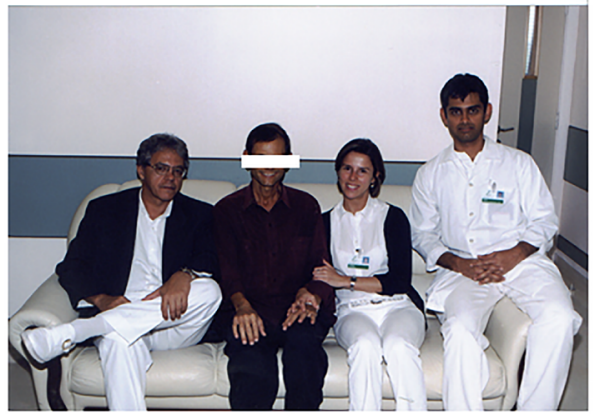

Panel A

Figure 3 Panel A. Prof.Orlando, Patient transplanted, Karina Dal'Sasso Mendes and Dr. Ajith Kumar Sankarankutty

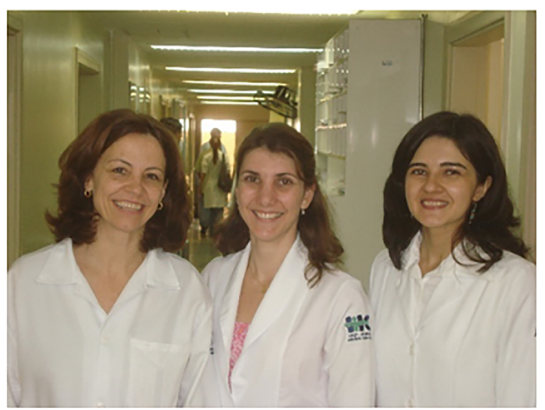

Panel B

Figure 3 Panel B. Clinical Team: Prof. Ana Martinelli. Andreza Teixeira and Fernanda Fernandes.

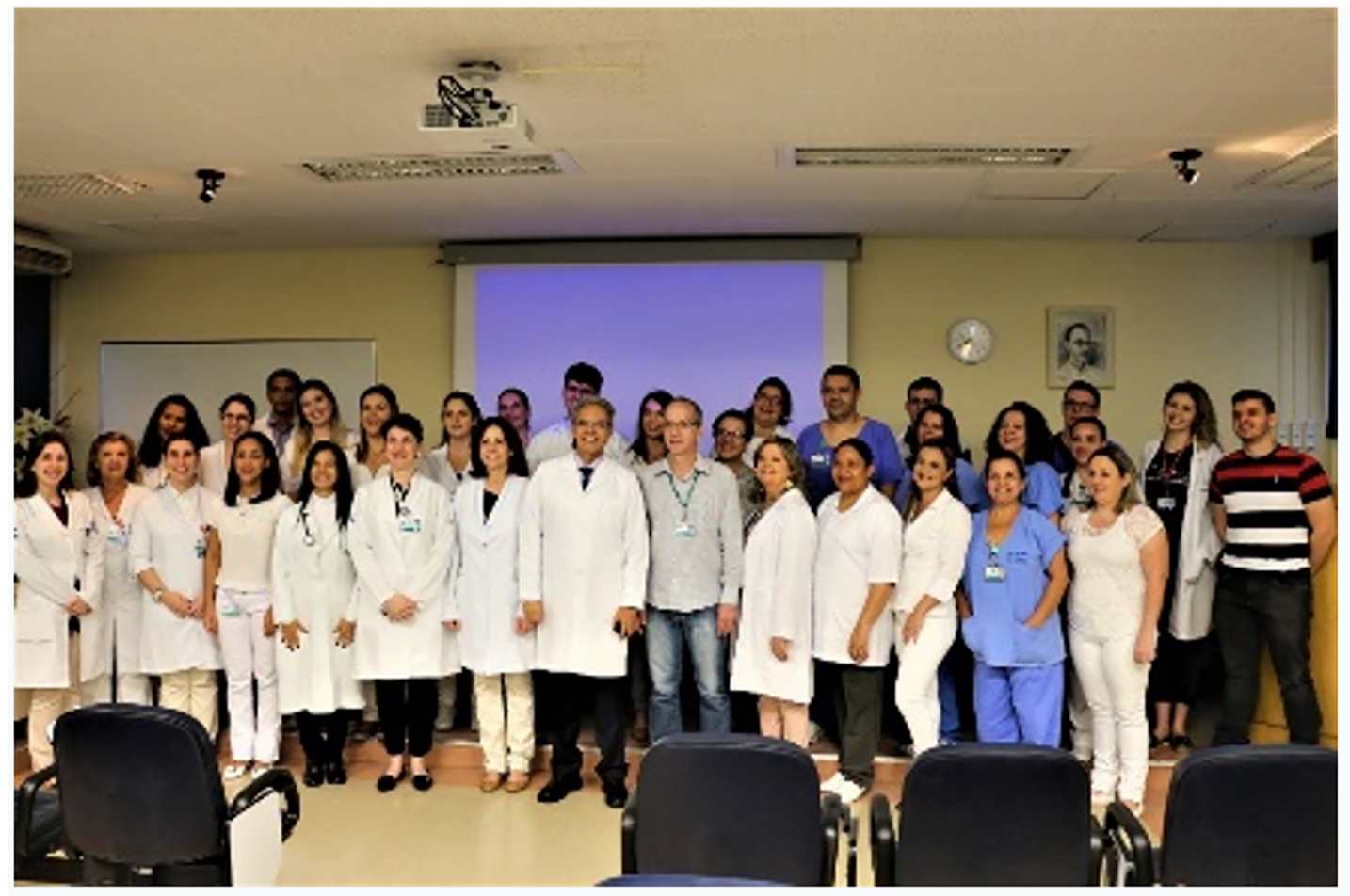

Figure 4 The Integrated Group of Liver Transplantation In 2017

A and B. Finally, the whole team in 2017, as shown in figure 4.

\section{Conclusion}

It took more than 10 years of preparation; a process that started with medical habilitation and culminated with the organization of the institutional structure as required for this complex procedure. "The idea of a liver transplant is to treat patients who are ill with an irreversible liver disease and return them to the society in a social, economic and health condition that permit them to do everything that a person without liver disease can do. It is an indescribable emotion to see a patient with no life 
perspectives returns to a healthy life. Obviously, there were several drawbacks along the initial path, which, however, were overcame one by one.

Brazil is among the countries that most perform organ transplants in the world. According to the Ministry of Health, about $90 \%$ of these procedures are funded by the SUS. Despite this advance, the programs have felt the impact of the Covid-19 pandemic. During a period of 15 days no liver transplant was performed in the State of São Paulo.

Thus, in the middle of the Covid-19 pandemic, we celebrate the 20th anniversary of the creation of the Institutional Program of Liver Transplantation, with emphasis on the first transplant performed during the first year of this century. We OCSJr and ALCM are currently retired, but we are obviously attached in an affective manner both to our colleagues and to the FMRP-USP institution. We believe that there are plenty of reasons to celebrate this anniversary.

\section{REERENCES}

1. Silva Junior OC. Primeiro Transplante de Fígado em Ribeirão Preto. Medicina (Ribeirão Preto) [Internet]. 30 de junho de 2001 [citado 29 de abril de 2021];34(2):119-20. Disponível em: https://www.revistas.usp.br/rmrp/article/ view/1199

2. França AV, Martinelli AL, Sankanrankutty AK, Rizzo CC, Silva Junior OC. Transplante de fígado: relato do primeiro caso realizado no hospital das clínicas da faculdade de medicina de Ribeirão Preto da universidade de São Paulo. Medicina (Ribeirão Preto) [Internet]. 30 de junho de 2001 [citado 29 de abril de 2021];34(2):194-9. Disponível em: https://www.revistas.usp.br/rmrp/ article/view/3105
3. Castro e Silva O, Martinelli AL. Editorial.Transplante defígado. Uma realidade no Hospital das Clínicas da FMRP-USP para o ano 2001. Medicina (Ribeirão Preto) 2000;33 (4): 373-6.2.

4. Silva Junior O de C e, Nejo P. Transplante de fígado como estratégia multidisciplinar de ensino de graduação. Medicina (Ribeirão Preto) [Internet]. 30 de março de 2010 [citado 29 de abril de 2021];43(1):35-8. Disponível em: https://www.revistas.usp.br/rmrp/ article/view/163

5. Meirelles FMJr, Salvalaggio $P$, Resende MB Evangelista AS, Della Guardia B, Matielo CEL et. al. Liver transplantation: history, outcomes and perspectives. Einstein (Sao Paulo).2015;13 (1): 149-52. Jan-Mar; 13(1): 149-52. doi:10.1590/S1679-45082015RW3164

6.Groth CG. Forty years of liver transplantation: personal recollections. Transplant Proc. $2008 ; 40(4): 1127-9$. doi: $10.1016 /$ j.transproceed.2008.03.025

7.Zarrinpar A, Busuttil R W Liver transplantation: past, present and future. Nat Rev Gastroenterol Hepatol. 2013 Jul;10(7): 434-40.doi:10.1038/nrgastro.2013.88.

8.Liver Transplantation Today: Where We Are Now and Where We Are Going Bodzin AS, Baker TB Liver Transpl. 2018;24(10):1470-75. doi: 10.1002/lt.25320.

9.Penn $\underline{I}$, Halgrimson CG, Starzl TE LIVER TRANSPLANTATION IN MAN Ann N Y Acad Sci. 1970 Jul; 170: 251-58. doi: $10.1111 /$ j.1749-6632.1970.tb37018.x

10. Bismuth $\mathrm{H}$. The need for a consensus agreement on indications of liver transplantation. Hepatology 1994 Jul;20(1 Pt 2):1S-2S.doi: 10.1016/02709139(94)90263-1

11. Silva OCJr, Souza FF, Teixeira AC, Mente Ênio D, Sankarankutty AK. Transplante de fígado em nosso meio. A evolução de um procedimento estratégico institucional. Medicina (Ribeirão Preto) [Internet]. 30 de dezembro de 2009 [citado 29 de abril de 2021];42(4):482-4. Disponível em: https://www. revistas.usp.br/rmrp/article/view/24 
Corresponding Author:

Orlando de Castro e Silva Jr

orlando@fmrp.usp.br

Editor:

Prof. Dr. Marcelo Riberto

Received in: may 02, 2021

Approved in: may 25, 2021 